\title{
Identifying Specific Cues and Contexts Related to Smoking Craving for the Development of Effective Virtual Environments
}

\author{
Olaya García-Rodríguez, Ph.D., Marta Ferrer-García, M.A., Irene Pericot-Valverde, B.A., \\ José Gutiérrez-Maldonado, Ph.D., Roberto Secades-Villa, Ph.D., ${ }^{2}$ and José L. Carballo, Ph.D. ${ }^{3}$
}

\begin{abstract}
Craving is considered the main variable associated with relapse after smoking cessation. Cue Exposure Therapy (CET) consists of controlled and repeated exposure to drug-related cues with the aim of extinguishing craving responses. Some virtual reality (VR) environments, such as virtual bars or parties, have previously shown their efficacy as tools for eliciting smoking craving. However, in order to adapt this technology to smoking cessation interventions, there is a need for more diverse environments that enhance the probability of generalization of extinction in real life. The main objective of this study was to identify frequent situations that produce smoking craving, as well as detecting specific craving cues in those contexts. Participants were 154 smokers who responded to an ad hoc self-administered inventory for assessing craving level in 12 different situations. Results showed that having a drink in a bar/pub at night, after having lunch/dinner in a restaurant and having a coffee in a cafe or after lunch/dinner at home were reported as the most craving-inducing scenarios. Some differences were found with regard to participants' gender, age, and number of cigarettes smoked per day. Females, younger people, and heavier smokers reported higher levels of craving in most situations. In general, the most widely cited specific cues across the contexts were people smoking, having a coffee, being with friends, and having finished eating. These results are discussed with a view to their consideration in the design of valid and reliable VR environments that could be used in the treatment of nicotine addicts who wish to give up smoking.
\end{abstract}

\section{Introduction}

$\mathbf{S}$ MOKING IS CURRENTLY ONE OF THE MOST IMPORTANT public health problems. Multicomponent treatments, which incorporate three intervention stages (preparation, quitting, and maintenance), are considered the treatment of choice for this problem. ${ }^{1}$ However, the high rates of relapse after the intervention (between $40 \%$ and $70 \%$ ) make it necessary to incorporate more effective relapse prevention strategies within this kind of programs. Intense craving has been systematically associated with relapse, ${ }^{2}$ while low craving levels after treatment predict the long-term success of the intervention. ${ }^{3,4}$ Pharmacological interventions do not appear to be effective in protecting smokers from urges related to cueinduced craving. ${ }^{5}$ Therefore, there is a need for treatments that deal with the effect of cue-induced craving. Cue Exposure Therapy (CET) consists of controlled and repeated exposure to drug-related cues, in order to reduce craving associated with these situations by extinction. According to learningbased theories, cue-induced craving is explained as a conditioned response (CR) established by a learned association between the cue (CS) and drug intake (US). ${ }^{6}$ In smoking cessation contexts, relapse is usually associated with cue-induced craving. ${ }^{7}$

Several experimental studies have examined smokers' responses to smoking-related and neutral cues, finding that smoking-related cues elicit greater reactivity across different domains (self-report, physiological, or behavioral). ${ }^{8}$ Smoking cues include viewing or holding a cigarette, ${ }^{9-11}$ videos showing smoking-related scenes, ${ }^{12,13}$ imagining

\footnotetext{
${ }^{1}$ Department of Personality, Assessment and Psychological Treatments, University of Barcelona, Barcelona, Spain.

${ }^{2}$ Department of Psychology, University of Oviedo, Oviedo, Spain.

${ }^{3}$ Department of Health Psychology, University Miguel Hernández, Elche, Spain.
} 
a scenario involving smoking, ${ }^{14,15}$ or being in smokers' natural environments in real time. ${ }^{16}$ Other studies have shown that controlled exposure to such cues can reduce craving levels after several repetitions, ${ }^{11,17}$ which has implications for clinical treatments. Furthermore, cue reactivity, and more specifically, heart-rate reactivity during cue-exposure, has been found to be a predictor for relapse after treatment. $^{18}$

Nevertheless, and despite the amount of basic research on the cue-exposure paradigm for smokers, few studies have assessed the utility of these findings for improving smoking cessation treatments, and the most substantial study found that cue exposure therapy did not improve standard cognitive-behavioral treatment. ${ }^{19}$ It is likely that the utility of these interventions is limited by the presentation method when imagery is used, and by the selection of cues that are too isolated when the presentation method is in vivo or photos. Traditionally, cues used are the most proximal stimuli to drug administration, such as smoking-related paraphernalia or holding or lighting a cigarette, but more complex environments should be used as cues for smoking. ${ }^{20}$ The use of virtual reality (VR) to provoke craving could be a good option, since it can permit exposure to specific smoking cues, such as lighters or ashtrays, but also to general contexts, such as a bar. Previous studies have reported the success of virtual environments (VE) for inducing smoking craving in a more effective way than other, more traditional presentation formats such as those mentioned above. ${ }^{21-25}$ Nevertheless, these studies are quite recent, and there is a need for more research on which VEs are suitable. The studies by Bordnick et al. employ VR to induce craving with good results, using virtual paraphernalia or avatars smoking in bars or parties as cues. ${ }^{23,26}$ Lee et al.'s studies used a virtual bar, ${ }^{27}$ while Baumann and Sayette (2006) developed a complex virtual world with smoking craving cues but based on the reported urges of just five smokers. Some previous research set out to identify the triggers or cues for smoking craving or relapse. Most literature on this topic has attempted to find the immediate antecedents of relapse, finding both negative and positive affect, $^{28,29}$ as well as social situations associated with previous smoking behavior, as the main precipitants of smoking. ${ }^{28,30}$ Shiffman et al. (1996) used electronic diaries in order to avoid retrospective methodology in the recording of craving or relapse situations, finding that most lapses $(78 \%)$ were associated with smoking cues and eating or drinking situations. Another study, which assessed the psychometric properties of 12 photos related to smoking, yielded excellent results, ${ }^{31}$ while several studies assessing smokers' self-efficacy in diverse situations ${ }^{32-34}$ offer a starting point for the use of reliability stimuli in VE-CET. In order to generalize the use of VR to clinical contexts, it is necessary to develop more diverse VEs based on larger samples of smokers' reports and on previous literature, with the aim of exposing participants to a greater number of situations and enhancing the probability of generalization of extinction. ${ }^{35}$

The main objective of this study was to identify common situations that produce smoking craving and specific craving cues in those scenarios, with a view to developing new, valid, and reliable VEs and improving VE-CET for smokers. A second objective was to identify differences in craving response to these situations as a function of different variables (gender, age, and number of cigarettes smoked per day).

\section{Materials and Methods}

\section{Participants}

Participants were 154 smokers (39\% male, 61\% female) with a mean age of 30.3 years (range 18-67) and a mean number of cigarettes smoked per day of 14.6. The snowball sampling method, starting with volunteer psychology undergraduates, was used to recruit the participants in three Spanish cities. Inclusion criteria were being aged 18 or older and having smoked 10 or more cigarettes per day over the previous 2 years. Those initially recruited were excluded if they met criteria for a current severe psychiatric disorder or other substance dependence, they had a smoking-related illness, or they were currently involved in smoking cessation activity.

\section{Instrument and procedure}

We developed an ad hoc self-administered inventory to assess the level of craving in 12 different situations: after having breakfast; after lunch/dinner at home; after lunch/ dinner in a restaurant; having a drink in a bar/pub at night; having a coffee in a cafe; watching TV or reading a book while relaxing at home; during a break between classes; during a break at work; waiting for a friend/bus on the street; working; studying for an exam; driving a car. These situations were selected based on previous studies assessing triggers for smoking, as well as smokers' self-efficacy in diverse situations. ${ }^{2,32-34}$ For each item, participants had to imagine the scene and indicate their desire to smoke on a Likert scale ranging from $0=$ "no desire" to $4=$ "very high desire," where applicable. For those situations graded with a score from 1 to 4, participants were also asked to write in a blank text box which stimulus (people, objects, sounds, etc.) present in that context made them wish to smoke. An open item was included at the end of the inventory for any other situation not included in the above list that the participant might consider relevant. All the instructions for responding to the instrument were included on it. The inventory showed good reliability (Cronbach's $\alpha=0.85$ ).

\section{Data analysis}

Various descriptive and frequency analyses in relation to participants' craving level and the most frequent stimuli in each situation were carried out. Student $t$ tests (after Levene's correction for inequality of variance) were conducted in order to assess gender differences with regard to craving desire in each situation. A one-way between-groups analysis of covariance was also carried out to compare craving levels as a function of age ( $\leq 26$ vs. $\geq 27$ ). Participants' number of cigarettes smoked per day was used as the covariate in this analysis. The same analysis was also used to compare desire for smoking, taking the number of cigarettes per day $(\leq 13$ vs. $\geq 14)$ as the independent variable and age as the covariate. Due to the number of statistical analyses conducted, a Bonferroni adjustment was made for tests on the 12 variables, setting the permissible type I error rate at $\alpha=0.0041(0.05 / 12)$. 
Table 1. Craving Levels Associated with Contexts

\begin{tabular}{lc}
\hline Situations & Mean craving level \pm SD \\
\hline $\begin{array}{l}\text { Having a drink in a bar/ } \\
\text { pub at night }\end{array}$ & $3.42 \pm 0.85$ \\
After having lunch/dinner & \\
$\quad$ in a restaurant & $3.19 \pm 0.94$ \\
Having a coffee in a cafe & \\
After having lunch/dinner & $2.97 \pm 1.06$ \\
$\quad$ at home & $2.77 \pm 1.12$ \\
During a break at work & \\
During a break between & $2.38 \pm 1.28$ \\
$\quad$ classes & $2.26 \pm 1.24$ \\
After having breakfast & \\
Studying for an exam & $2.16 \pm 1.29$ \\
Waiting for a friend/bus & $2.11 \pm 1.39$ \\
$\quad$ on the street & $1.74 \pm 1.25$ \\
Watching TV or reading a book & \\
$\quad$ while relaxing at home & $1.32 \pm 1.15$ \\
Driving a car & \\
Working & $1.27 \pm 1.22$ \\
\end{tabular}

The statistical software used was SPSS (V15; SPSS, Inc., Chicago, IL).

\section{Results}

\section{Contexts}

Table 1 shows the mean craving level for each risk situation assessed. As we can see, the highest levels of reported craving are related to having a drink in a bar/pub at night and after having lunch/dinner in a restaurant. On the opposite side, driving a car and watching $T V$ or reading a book while relaxing at home were the least craving-inducing situations.

The open item resulted in 30 new and different situations, but most of them were reported by no more than one or two persons. Only one of these new contexts was mentioned by a significantly greater number of participants. A total of 23 participants $(19.9 \%)$ mentioned a desire to smoke after having sexual relations.

Gender, age, and number of cigarettes per day. Table 2 shows the comparison of craving levels by gender, age, and mean number of cigarettes smoked per day.

With regard to the gender variable, we found statistically significant differences between men and women in three contexts: having a coffee in a cafe, during a break between classes, and studying for an exam. In all three situations, women reported a greater desire for smoking than men. Males and females did not differ significantly in the other two variables considered (age or number of cigarettes per day).

Participants were divided by age into two subgroups of equal size. One subgroup included participants under the age of 27 and the second subgroup those aged 27 or over. Participants in the two groups differed in the number of cigarettes smoked per day $\left(M_{\leq 26}=13.4, M_{\geq 27}=15.8 ; t_{(152)}=-2.77\right.$, $p=0.006)$, so that this variable was included as a covariate in the analyses to control its effect. We found some differences in craving levels between the younger and the older group. In this case, having a drink in a bar/pub at night, after having lunch or dinner in a restaurant, studying for an exam, waiting for a

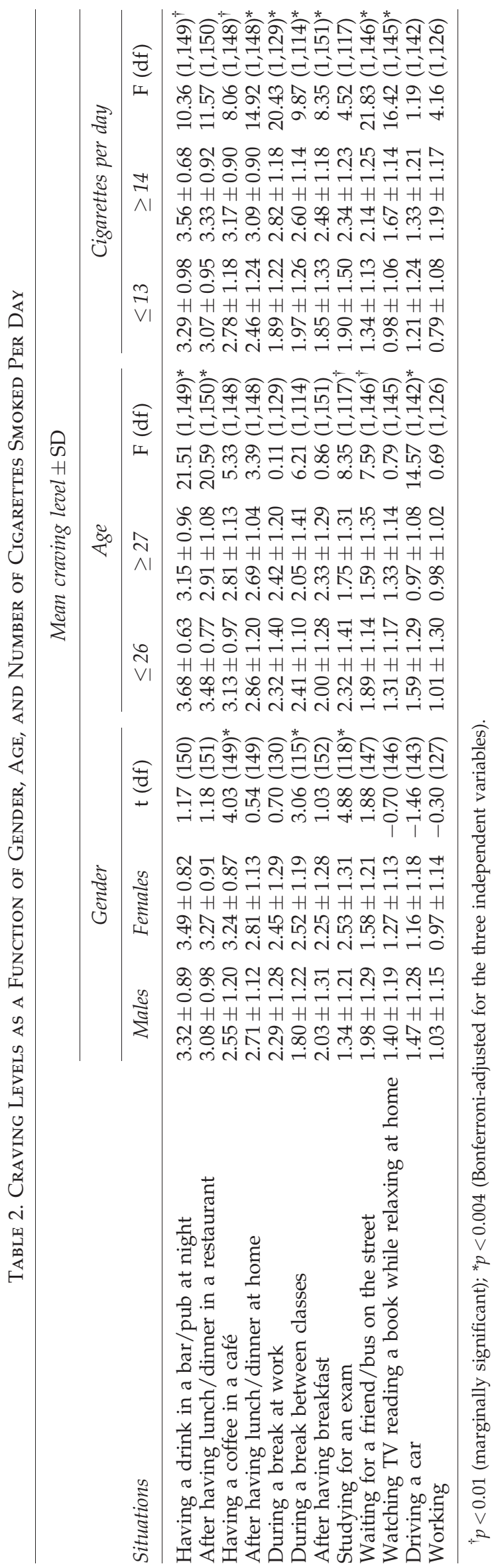


friend/bus on the street, and driving a car all produced more craving in the younger group than in the older group.

Finally, we compared the two subgroups that resulted from dividing the sample according to number of cigarettes smoked per day. The cut-off point that left $50 \%$ of the participants in each group was smoking less than 14 cigarettes or smoking 14 or more. Participants in the two groups differed in age $\left(M_{\leq 13}=28.3, M_{\geq 14}=32.2 ; t_{(152)}=-2.18, p=0.03\right)$, so that this variable was also included as a covariate. In this case, differences were detected in most of the situations, with the exception of after having lunch/dinner in a restaurant, studying for an exam, driving a car, and working. For all the cases, those who smoked 14 or more cigarettes per day reported higher craving levels.

\section{Specific cues}

Data about specific stimuli that could contribute to increasing participants' smoking craving in the proposed situations were also collected. In order to deal with the most relevant outcomes, we report here only those cues that were mentioned by at least $10 \%$ of the participants $(n \geq 15)$.

Having a drink (51.9\%), being with friends $(40.9 \%)$, people smoking $(33.7 \%)$, music $(22.7 \%)$, and people around $(16.2 \%)$ were the most frequently reported cues in the pub at night. Being with friends $(38.9 \%)$, having finished eating $(27.2 \%)$, people smoking $(21.4 \%)$, having a coffee $(16.2 \%)$, people around $(11.0 \%)$, and having a drink $(10.3 \%)$ were the most frequently mentioned specific cues after having lunch/dinner in a restaurant. Similarly, the most frequent stimuli when having a coffee in a cafe were the coffee (46.1\%), being with friends $(37.0 \%)$, and people smoking (19.5\%). After having lunch/ dinner at home, the specific cues cited were having finished eating $(51.2 \%)$, watching television $(12.3 \%)$, having a coffee $(11 \%)$, and being with relatives $(10.3 \%)$. Once again, coffee $(32.4 \%)$ and having finished eating $(12.3 \%)$ were cues reported for after having breakfast. People smoking (23.3\%) and being with classmates $(12.3 \%)$ were the most frequently mentioned specific cues during a break between classes. In contrast, having nothing to do (55.1\%) and people around (11.6\%) were the main smoking-triggering cues when waiting for a friend/bus on the street. Finally, television (18.8\%) when relaxing at home and music $(10.3 \%)$ while driving a car were also some of the most often-cited specific cues. No specific cues were reported by at least $10 \%$ of the participants for the rest of the situations: during a break at work, working, or studying for an exam.

\section{Discussion}

The main objective of this study was to identify common situations that produce smoking craving, as well as to detect specific craving cues in those contexts in order to develop more effective VEs that could be used within the cue-exposure paradigm.

The results of this study showed that some contexts were associated with higher self-reported craving levels than others. These scenarios were: having a drink in a bar/pub at night, after having lunch/dinner in a restaurant, having a coffee in a cafe,
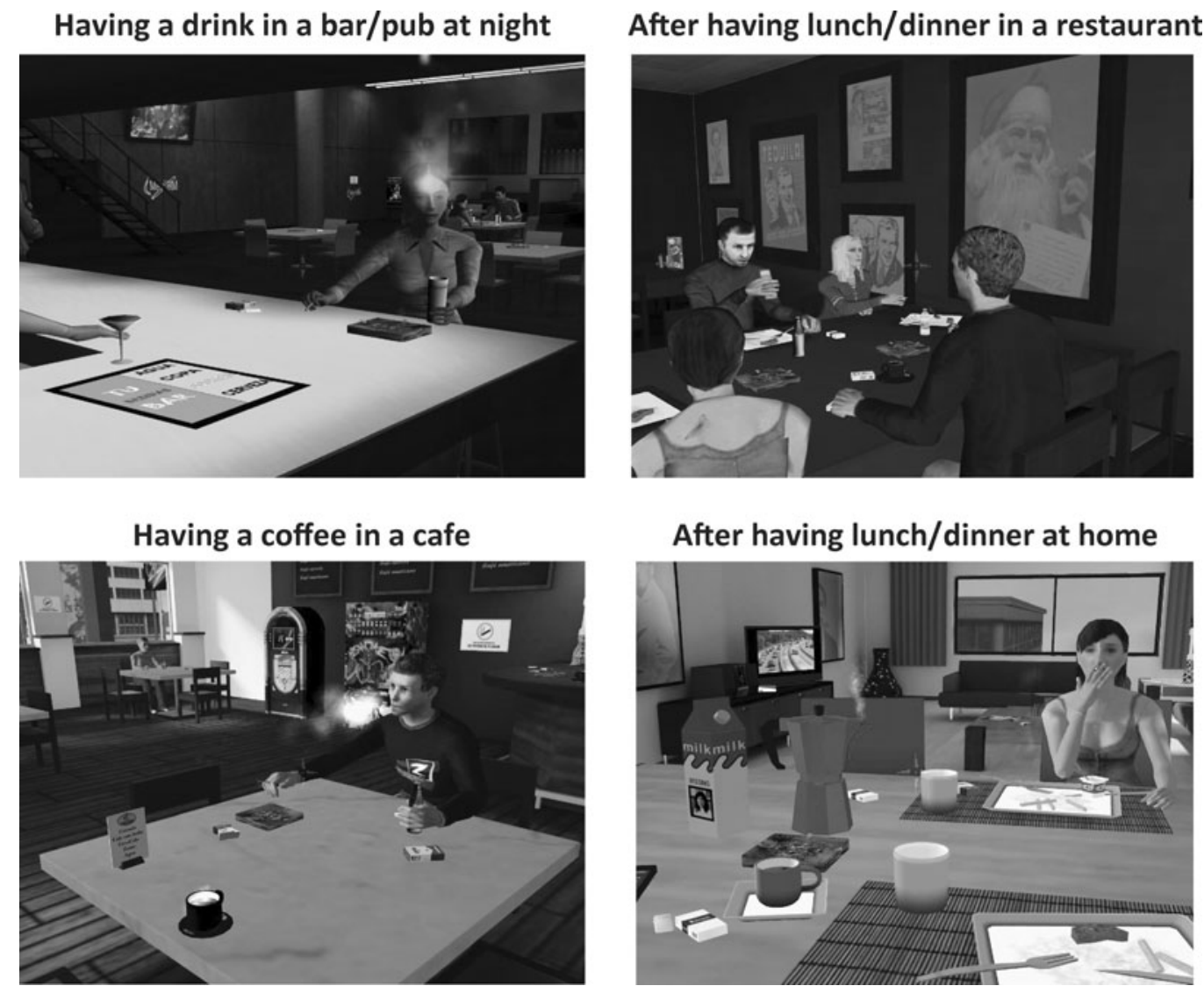

FIG. 1. Virtual environments based on the results. 
and after having lunch/dinner at home. The rest of the proposed situations were also related to the desire to smoke, but showed lower craving levels or were reported with less frequency. This information could be useful when working with exposure procedures for extinguishing conditioned responses in which it is necessary to increase the intensity of the conditioned stimulus gradually using, as in this case, different situations that produce craving.

Our results are in the same line as those of previous studies that attempted to identify risk situations for smoking. Social or food situations in which people smoke were also identified in previous studies. ${ }^{2,33}$ However, what is new in this study is that we have identified both contexts or situations and specific cues that can produce smoking craving. This knowledge is necessary when developing VEs that aim to reproduce real situations. Furthermore, the sample size used in the present study is more representative than those used in previous studies related to VR. ${ }^{21}$

With regard to the specific stimuli in each of these contexts, we saw in the results section that some of the specific cues were cited across the situations. These most widely cited cues included people smoking, having a coffee, being with friends, and having finished eating. All such specific cues should be considered in the design of valid and reliable VR environments aimed at producing craving in smokers, whether or not they match the scenarios proposed here.

On the other hand, we should bear in mind that some situations that can trigger smoking, such as the cited after having sexual relations, would be difficult to represent in VEs, so having a wide range of scenarios is necessary for facilitating the generalization of extinction when using a cueexposure treatment paradigm. At the same time, using VEs permits continuous monitoring of craving while the subject is exposed. This provides a unique opportunity to test unexpected cues that researchers could not have predicted, and this advantage is only comparable with those offered by naturalistic or real situations.

Some individual variables were also studied. We found that mean desire for smoking in most situations was greater in females than in males. Despite the fact that some of the situations did not reach statistical significance, there was a clear trend for higher self-reported craving among female participants. Some studies have also found that females show higher reactivity than males to smoking-related cues, according to both self-reported craving measures ${ }^{36}$ and psychophysiological measures such as blood pressure or EEG. ${ }^{37,38}$ Likewise, research has found the effects of tobacco withdrawal symptoms to be greater in women than in men. ${ }^{39}$ As regards participants' age, we found no linear trend, but in those situations where significant differences were detected, they showed greater craving among younger respondents. Nevertheless, these differences could also be explained by the fact that some specific situations, such as having a drink in a bar/pub or studying for an exam, are more frequent in younger than older people. Finally, a significant relationship was found between number of cigarettes smoked per day and craving experienced in the VEs: the more cigarettes smoked, the higher the craving. These results are in the same direction as those of previous studies, which found a direct relationship between reactivity and number of cigarettes or nicotine dependence. ${ }^{40,41}$ However, other studies have also shown the opposite relationship, whereby lower dependency levels were related to increased reactivity, ${ }^{42}$ or it was at least as strong as that of heavy smokers. ${ }^{43}$ Even so, it must be pointed out that, in our sample, even the participants who reported the highest number of cigarettes smoked per day were light smokers compared to those in the mentioned studies. Thus there is a need for further studies to determine whether this relationship is linear or whether, indeed, reactivity to craving stimuli or situations decreases in heavy smokers compared to light smokers such as those taking part in our study. Despite the use of Bonferroni correction in these analyses, we have also reported those variables that were found to be marginally significant. Therefore, findings significant at $p<0.01$ should be interpreted with caution.

This data on individual differences could prove useful for determining exposure parameters. Future research might consider these results with the objective of analyzing whether higher levels of self-reported craving could be correlated to a need for longer exposure periods to extinguish the conditioned response. Thus it might be interesting to know whether females, younger people, and light smokers are more resistant to extinction than males, older people, and heavier smokers.

Some limitations of this study should be mentioned. On the one hand, we should bear in mind that these self-report craving results are based on responses to an inventory. A more reliable way of obtaining results would be to use a naturalistic assessment of craving levels at the time when people are actually in the relevant contexts and imagination or memory do not play such a crucial role. On the other hand, the mean number of cigarettes smoked per day in our sample was quite low (less than 14). Tobacco-related studies usually consider heavy smokers as those who smoke more than 20 cigarettes per day, which would suggest that this category of smokers is not represented in our study.

Finally, we should like to illustrate these results with some VEs that are being developed based on the results of our study. Figure 1 shows images of the four situations that were reported as the strongest smoking triggers considering both contexts and specific cues. This technology will be used in a future trial whose objective will be to assess the efficacy of CET though VR for smoking cessation.

\section{Acknowledgment}

This work was supported by a Ministry of Science and Innovation (MICIIN) grant from the Spanish Government, Ref. PSI2008-05938/PSIC.

\section{Disclosure Statement}

No competing financial interests exist.

\section{References}

1. U.S. Department of Health and Human Services. (1996) Clinical Practice Guideline no. 18. Smoking cessation. Washington, DC: US Government Printing Office.

2. Shiffman S, Paty JA, Gnys M, et al. First lapses to smoking: Within-subjects analysis of real-time reports. Journal of Consulting \& Clinical Psychology 1996; 64:366-79.

3. Ferguson SG, Shiffman S, Gwaltney CJ. Does reducing withdrawal severity mediate nicotine patch efficacy? A randomized clinical trial. Journal of Consulting \& Clinical Psychology 2006; 74:1153-61. 
4. Killen JD, Fortmann SP. Craving is associated with smoking relapse: Findings from three prospective studies. Experimental \& Clinical Psychopharmacology 1997; 5:137-42.

5. Ferguson SG, Shiffman S. The relevance and treatment of cue-induced cravings in tobacco dependence. Journal of Substance Abuse Treatment 2009; 36:235-43.

6. Niaura RS, Rohsenow DJ, Binkoff JA, et al. Relevance of cue reactivity to understanding alcohol and smoking relapse. Journal of Abnormal Psychology 1988; 97:133-52.

7. Marlatt GA, Gordon JR. (1985) Relapse prevention. Maintenance strategies in the treatment of addictive behaviors. New York: The Guilford Press.

8. Drummond DC, Tiffany ST, Glautier S, et al. (1995) Addictive behaviour. Cue exposure theory and practice. Chichester, England: John Wiley.

9. Sayette MA, Hufford MR. Effects of cue exposure and deprivation on cognitive resources in smokers. Journal of $\mathrm{Ab}$ normal Psychology 1994; 103:812-8.

10. Upadhyaya HP, Drobes DJ, Thomas SE. Reactivity to smoking cues in adolescent cigarette smokers. Addictive Behaviors 2004; 29:849-56.

11. LaRowe SD, Saladin ME, Carpenter MJ, et al. Reactivity to nicotine cues over repeated cue reactivity sessions. Addictive Behaviors 2007; 32:2888-99.

12. Lim HK, Pae CU, Joo RH, et al. fMRI investigation on cueinduced smoking craving. Journal of Psychiatric Research 2005; 39:333-5.

13. Tong C, Bovbjerg DH, Erblich J. Smoking-related videos for use in cue-induced craving paradigms. Addictive Behaviors 2007; 32:3034-44.

14. Drobes DJ, Tiffany ST. Induction of smoking urge through imaginal and in vivo procedures: Physiological and selfreport manifestations. Journal of Abnormal Psychology 1997; 106:15-25.

15. Erblich J, Bovbjerg DH. In vivo versus imaginal smoking cue exposures: Is seeing believing? Experimental \& Clinical Psychopharmacology 2004; 12:208-15.

16. Warthen MW, Tiffany ST. Evaluation of cue reactivity in the natural environment of smokers using ecological momentary assessment. Experimental \& Clinical Psychopharmacology 2009; 17:70-7.

17. Tiffany ST, Cox LS, Elash CA. Effects of transdermal nicotine patches on abstinence-induced and cue-elicited craving in cigarette smokers. Journal of Consulting \& Clinical Psychology 2000; 68:233-40.

18. Abrams DB, Monti PM, Carey KB, et al. Reactivity to smoking cues and relapse: Two studies of discriminant validity. Behaviour Research \& Therapy 1988; 26:225-33.

19. Niaura R, Abrams DB, Shadel WG, et al. Cue exposure treatment for smoking relapse prevention: A controlled clinical trial. Addiction 1999; 94:685-95.

20. Conklin CA. Environments as cues to smoke: Implications for human extinction-based research and treatment. Experimental \& Clinical Psychopharmacology 2006; 14:12-19.

21. Baumann SB, Sayette MA. Smoking cues in a virtual world provoke craving in cigarette smokers. Psychology of Addictive Behaviors 2006; 20:484-9.

22. Bordnick PS, Graap KM, Copp H, et al. Utilizing virtual reality to standardize nicotine craving research: A pilot study. Addictive Behaviors 2004; 29:1889-94.

23. Bordnick PS, Graap KM, Copp HL, et al. Virtual reality cue reactivity assessment in cigarette smokers. CyberPsychology \& Behavior 2005; 8:487-92.
24. Lee J, Lim Y, Graham SJ, et al. Nicotine craving and cue exposure therapy by using virtual environments. CyberPsychology \& Behavior 2004; 7:705-13.

25. Saladin ME, Brady KT, Graap K, et al. A preliminary report on the use of virtual reality technology to elicit craving and cue reactivity in cocaine dependent individuals. Addictive Behaviors 2006; 31:1881-94.

26. Traylor AC, Bordnick PS, Carter BL. Assessing craving in young adult smokers using virtual reality. The American Journal on Addictions 2008; 17:436-40.

27. Lee JH, Ku J, Kim K, et al. Experimental application of virtual reality for nicotine craving through cue exposure. CyberPsychology \& Behavior 2003; 6:275-80.

28. Baer JS, Lichtenstein E. Classification and prediction of smoking relapse episodes: An exploration of individual differences. Journal of Consulting \& Clinical Psychology 1988; 56:104-10.

29. Shiffman S. Relapse following smoking cessation: A situational analysis. Journal of Consulting \& Clinical Psychology 1982; 50:71-86.

30. Borland R. Slip-ups and relapse in attempts to quit smoking. Addictive Behaviors 1990; 15:235-45.

31. Carter BL, Robinson JD, Lam CY, et al. A psychometric evaluation of cigarette stimuli used in a cue reactivity study. Nicotine \& Tobacco Research 2006; 8:361-9.

32. Condiotte MM, Lichtenstein E. Self-efficacy and relapse in smoking cessation programs. Journal of Consulting \& Clinical Psychology 1981; 49:648-58.

33. Gwaltney CJ, Shiffman S, Norman GJ, et al. Does smoking abstinence self-efficacy vary across situations? Identifying context-specificity within the Relapse Situation Efficacy Questionnaire. Journal of Consulting \& Clinical Psychology 2001; 69:516-27.

34. Mudde AN, Kok G, Strecher VJ. Self-efficacy as a predictor for the cessation of smoking: Methodological issues and implications for smoking cessation programs. Psychology \& Health 1995; 10:353-67.

35. Havermans RC, Jansen AT. Increasing the efficacy of cue exposure treatment in preventing relapse of addictive behavior. Addictive Behaviors 2003; 28:989-94.

36. Dickmann PJ, Mooney ME, Allen SS, et al. Nicotine withdrawal and craving in adolescents: Effects of sex and hormonal contraceptive use. Addictive Behaviors 2009; 34: 620-3.

37. Knott VJ, Naccache L, Cyr E, et al. Craving-induced EEG reactivity in smokers: Effects of mood induction, nicotine dependence and gender. Neuropsychobiology 2008; 58: 187-99.

38. Niaura R, Shadel WG, Abrams DB, et al. Individual differences in cue reactivity among smokers trying to quit: Effects of gender and cue type. Addictive Behaviors 1998; 23: 209-24.

39. Leventhal AM, Waters AJ, Boyd S, et al. Gender differences in acute tobacco withdrawal: Effects on subjective, cognitive, and physiological measures. Experimental \& Clinical Psychopharmacology 2007; 15:21-36.

40. Donny EC, Griffin KM, Shiffman S, et al. The relationship between cigarette use, nicotine dependence, and craving in laboratory volunteers. Nicotine \& Tobacco Research 2008; 10:934-42.

41. Payne TJ, Smith PO, Sturges LV, et al. Reactivity to smoking cues: Mediating roles of nicotine dependence and duration of deprivation. Addictive Behaviors 1996; 21:139-54. 
42. Watson NL, Carpenter MJ, Sayette MA, et al. (2009) Could low dependent smokers be more cue reactive than high dependent smokers? 71st Annual Scientific Meeting of the College on Problems of Drug Dependence (CPDD), Reno, Nevada.

43. Shiffman S, Paty J. Smoking patterns and dependence: Contrasting chippers and heavy smokers. Journal of Abnormal Psychology 2006; 115:509-23.
Address correspondence to: Dr. Olaya García Rodríguez Facultad de Psicología Paseo Valle de Hebrón, 171 08035, Barcelona Spain

E-mail: olayagarcia@ub.edu 
